\title{
Research on Job Satisfaction of Primary and Secondary School PE Teachers
}

\author{
Lin Hao ${ }^{1, ~ a}$, Yang Tianchao, ${ }^{2,}$, Li Shan ${ }^{1}$ \\ ${ }^{1}$ School of Physical Education, Chengdu University, Chengdu 610000, Sichuan China \\ ${ }^{2}$ School of Physical Education, Southwest University for Nationalities, Chengdu 610000, Sichuan, \\ China

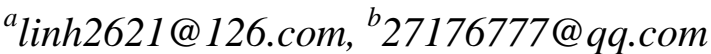

Keywords: primary and secondary school; PE teachers; job satisfaction; countermeasures

\begin{abstract}
This paper investigates the current job satisfaction level of 300 PE teachers in 20 primary and secondary schools in Shandong Province. According to the research result, PE teachers in primary secondary schools have median level of job satisfaction in general; highest satisfaction level in both working and interpersonal relationship; and relative low level of school system, leadership supporting, and working environment. By comparison, male PE teachers have higher job satisfaction than female PE teachers in this career, no other significant differences beside gender dimension. The job satisfaction degree of young PE teachers with 0-2 years of teaching experience has higher leadership support than other teaching ages of PE teachers. In the two dimensions of school system, salary and welfare, the satisfaction of senior teachers is significantly higher than intermediate teachers and junior teachers.
\end{abstract}

\section{Introduction}

It's important that the development of education is of a tight connection with teachers' staff quality and the stability which depends on their job satisfaction. It is all teacher's feelings and opinions toward their work and working conditions.PE teachers are the core of training healthy physical education personnel and are one of the school's main human resources. The quality of education is greatly beneficial for their mental health, work efficiency and rights, it's also have more influence to job performance. Therefore, by conducting empirical research, describing and analyzing the data, understanding the status quo and problems of the job satisfaction of PE teachers in primary and secondary schools, and making suggestions, it is important to enhance the mental health of primary and secondary school PE teachers, improve work efficiency, and protect the rights of physical education teacher's significance.

\section{Research Objects and Methods}

\subsection{Research objects}

In this study, 20 representative primary and secondary school PE teachers in Shandong Province 
were selected as the survey subjects. In the process of research, we totally sent out 300 questionnaires and got back 223 ones are available.

\subsection{Research methods}

\subsubsection{Questionnaire}

In the survey questionnaire, the design of the job satisfaction measurement scale for primary and secondary school PE teachers draws on the results of Liu Qingliang's and Zhu Geweimin's research, and we combine the characteristics of primary and secondary school PE teachers with the research needs in the research, problems are modified and deleted.The scale formed includes six dimensions: the school system, salary and welfare, working itself, leadership support, work environment, and interpersonal relationships, and 24 items (Table 1).

Table 1 Job Satisfaction of PE teachers

\begin{tabular}{|c|c|}
\hline Dimensions & Items \\
\hline Management System & $\begin{array}{l}\text { The school reward system is clear and reasonable, which will help } \\
\text { improve job performance } \\
\text { School rules and regulations are more reasonable } \\
\text { The establishment of various institutions of the school is democratic } \\
\text { School administrative work can meet the needs of physical education } \\
\text { teaching }\end{array}$ \\
\hline $\begin{array}{l}\text { Remuneration } \\
\text { and benefits }\end{array}$ & $\begin{array}{l}\text { Compared with teachers from other subjects of this school, I am } \\
\text { satisfied with my reward } \\
\text { It is fairer to distribute remuneration among PE teachers. } \\
\text { The school's various welfare conditions are relatively good } \\
\text { The actual amount of compensation is more in line with expectations } \\
\text { The work of PE teachers is very safe } \\
\text { I can get effective business training regularly from school }\end{array}$ \\
\hline Work itself & $\begin{array}{l}\text { I have a greater interest in the profession of PE teachers } \\
\text { I can get a strong sense of accomplishment from my sports work } \\
\text { My work can often be recognized and praised by others } \\
\text { Students can actively cooperate with my physical education work } \\
\text { I intend to engage in physical education for a long time }\end{array}$ \\
\hline Leadership support & $\begin{array}{l}\text { Leadership can be affirmed based on my performance } \\
\text { School leaders attach great importance to physical education } \\
\text { School leaders give support and help to my work }\end{array}$ \\
\hline Working environment & $\begin{array}{l}\text { Advantageous working conditions such as school sports facilities and } \\
\text { facilities } \\
\text { PE teachers' Work Environment Safety and Health } \\
\text { I am satisfied with the school and the surrounding natural environment }\end{array}$ \\
\hline Human relations & $\begin{array}{l}\text { Work colleagues can help each other } \\
\text { Happy exchanges and cooperation between colleagues } \\
\text { I feel that the relationship between colleagues is very harmonious }\end{array}$ \\
\hline
\end{tabular}

The questionnaire used Rickett's five-point scale method to measure the satisfaction of primary and middle school PE teachers with working from 1-5 degrees (completely disagree, disagree, 
uncertain, agree, and completely agree). The reliability test commonly used in Rickett scales is Cronbach's Alpha coefficient. However, many experts have different views on the acceptable minimum reliability factor value. we chose the point of Devellis, who believes that the coefficient value of $0.8<\mathrm{a}<0.9$ is very good, $0.7<\mathrm{a}<0.8$ is quite good, $0.65<\mathrm{a}<0.7$ is the minimum acceptable value, and less than 0.65 should be revised questionnaire. SPSS22.0 statistical analysis software was used to test the reliability of the scale. After testing, the overall reliability of the scale and the reliability coefficient of each dimension have met the requirements. The results are shown in Table 2.

Table 2 Job satisfaction metrics reliability test

\begin{tabular}{ccc}
\hline Variable name & Index number & Reliability coefficient \\
\hline School system & 4 & 0.755 \\
Remuneration and benefits & 6 & 0.791 \\
Work itself & 5 & 0.767 \\
Leadership support & 3 & 0.738 \\
Working environment & 3 & 0.670 \\
Human relations & 3 & 0.693 \\
Total table & 24 & 0.921 \\
\hline
\end{tabular}

\subsubsection{Mathematical statistics}

The spss22.0 statistical analysis software was used to perform descriptive statistical analysis and comparative analysis of the data.

\section{Researching Resultant Analysis}

\subsection{Demographic analysis of the sample}

The data were analysed with SPSS22.0 software. The demographic characteristics of the sample were described as follows. See Table 3.

Table 3 Demographic characteristics of the sample $\mathrm{N}=223$

\begin{tabular}{cccc}
\hline Statistical variables & Sample project & Frequency & Percentage \\
\hline Gender & Male & 126 & $56.5 \%$ \\
& Female & 97 & $43.5 \%$ \\
Teaching age & $\leq 2$ years & 28 & $12.6 \%$ \\
& 3-7 years & 55 & $24.7 \%$ \\
& 8-18 years & 94 & $42.2 \%$ \\
\multirow{3}{*}{ Job title } & 19-25 years & 35 & $15.7 \%$ \\
& $>25$ years & 11 & $4.9 \%$ \\
& Primary & 62 & $27.8 \%$ \\
& Middle & 114 & $51.1 \%$ \\
& High & 47 & $21.1 \%$ \\
\hline
\end{tabular}

\subsection{Overall satisfaction analysis}

As can be seen from the measurement results, the overall job satisfaction of primary and secondary school PE teachers in Shandong Province is 3.252, which is a moderate level. Judging from the dimensions of satisfaction, the highest degree of satisfaction for sports teachers are the 
interpersonal relationships and the working itself (The averages are 3.864 and 3.776, respectively), which are correspond to the upper middle level, indicating that with the harmonious relations among colleagues, primary and secondary school PE teachers themselves are fond of their jobs and accustomed to working methodically. The average of the school system and working environment is in the range of 3 to 5 , which is a moderate level, indicating that a lower contentment level. Meanwhile, the average of remuneration, welfare and leadership support were no more than 3(It is only 2.803 and 2.905, respectively), which is a degree below the middle level, showing that primary and secondary school teachers are less satisfied with salary and welfare, as well as the leadership support.

Table 4 Overall status of job satisfaction $\mathrm{N}=223$

\begin{tabular}{lll}
\hline Variable name & $\mathrm{M}$ & $\mathrm{SD}$ \\
\hline School system & 3.119 & 0.697 \\
Remuneration and benefits & 2.803 & 0.686 \\
Work itself & 3.776 & 0.713 \\
Leadership support & 2.905 & 0.875 \\
Working environment & 3.208 & 0.853 \\
Human relations & 3.864 & 0.570 \\
Total satisfaction & 3.362 & 0.691 \\
\hline
\end{tabular}

\subsection{Analysis on the job satisfaction among PE teachers of the different genders.}

Two independent sample distribution location tests were used to compare gender differences in job satisfaction. The results show that there indeedly are gender differences in the satisfaction of primary and middle school PE teachers in the dimension of the working itself, as shown in Table 5. Among them, the male teacher 's satisfaction score reached 4.09 (Figure 1), but the female teacher's was only 3.62. The satisfaction of the male teacher in this dimension of the work itself is much greater than that of the female. First of all, from a physiological difference point of view, since men are more like sports than women, they can show their specialty in physical education: Not only they can teach in classes but also exercise together with students. Male teachers have more fun than female teachers in physical education. Secondly, the physical teaching tasks are heavy. During this period, the primary and secondary school teachers also have to undertake extra exercises such as morning exercises, class exercises, and various types of organizational sports activities, which only adds to the burden. This requires primary and secondary school PE teachers to spend more time on the job: Compared to male teachers, female teachers spent less time on working because they need to take care of their family in addition to school work. Besides, The physical working in primary and secondary schools, male sports teachers have more opportunities to be promoted management positions than female PE teachers. Maybe that's why male teachers are more satisfied with the work than female teachers.

Table 5 Differences in Job Satisfaction of PE Teachers of Different Genders

\begin{tabular}{llll}
\hline Variable name & Mann-Whitney & $\mathrm{Z}$ & $\mathrm{P}$ \\
\hline School system & 7275.000 & -0.276 & 0.081 \\
Remuneration and benefits & 6026.000 & -0.831 & 0.209 \\
Work itself & 5401.000 & -0.956 & 0.001 \\
Leadership support & 8114.000 & -2.962 & 0.253 \\
working environment & 5155.000 & -1.2931 & 0.108 \\
Human relations & 3960.500 & -1.538 & 0.221 \\
Total satisfaction & 5029.000 & -3.292 & 0.136 \\
\hline
\end{tabular}




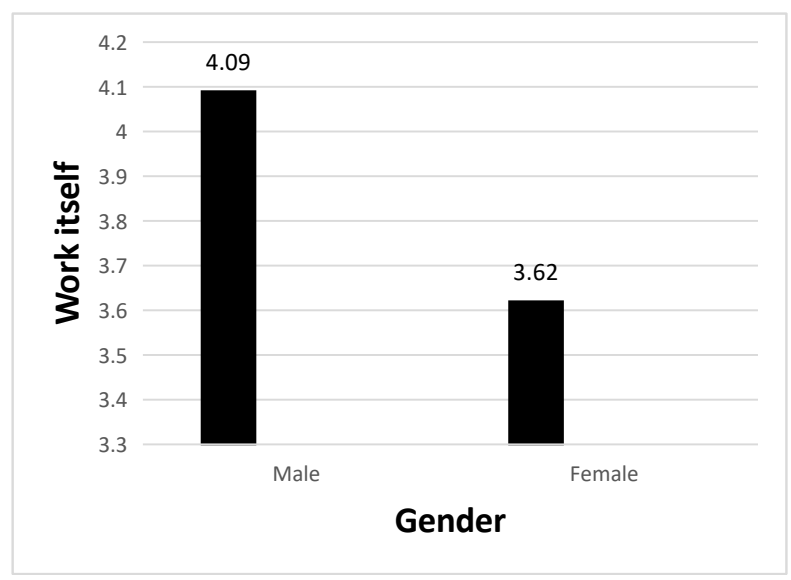

Figure 1 Comparison of different genders of PE teachers

\subsection{Analysis on the difference of seniority in different stage of contents.}

The teaching career of PE teachers is a phased process of continuous development. Each stage has its own characteristics.0-2 years are the adaptation period, 3-7 years are the growth period, and 8-18 years are the rising period. 19- 25 years are maturation periods and 25 years or more are expert periods. The median test method was used to compare the differences in the job satisfaction of PE teachers in primary and secondary schools. The results are shown in Table 6. There are significant differences in the leadership support of primary and secondary school PE teachers of different teaching ages. It can be seen by comparing the mean value of different teaching ages for the leadership support dimension (Figure 2). The satisfaction rate of 0-2 years of teaching age of PE teachers is much higher than that of teachers of other age groups. The differences among teachers of other age groups are relatively small. This shows that the young teachers of the teaching age of $0-2$ years have just added jobs and their work enthusiasm is relatively high. When the leaders arrange work, the young teachers get more chances to participate, and they are in the aim of training new people. The leaders will also give young people Teachers strongly support it. Second, the young teachers who have just joined the work are basically unmarried. Therefore, they can get more support and care from their units and leaders in their lives.PE teachers generally have lower scores in leadership support. The reason may be that physical education in primary and secondary schools in China is relatively unappreciated. Compared with teachers in other subjects, PE teachers receive lower leadership support.

Table 6 Differences in Job Satisfaction of PE Teachers of Different Teaching Ages

\begin{tabular}{cccc}
\hline Variable name & Chi-square test & DF & P \\
\hline School system & 3.051 & 2 & 0.567 \\
Remuneration and benefits & 3.155 & 2 & 0.394 \\
Work itself & 4.096 & 2 & 0.328 \\
Leadership support & 3.395 & 2 & 0.000 \\
working environment & 2.965 & 2 & 0.523 \\
Human relations & 5.476 & 2 & 0.248 \\
Total satisfaction & 5.905 & 2 & 0.201 \\
\hline
\end{tabular}




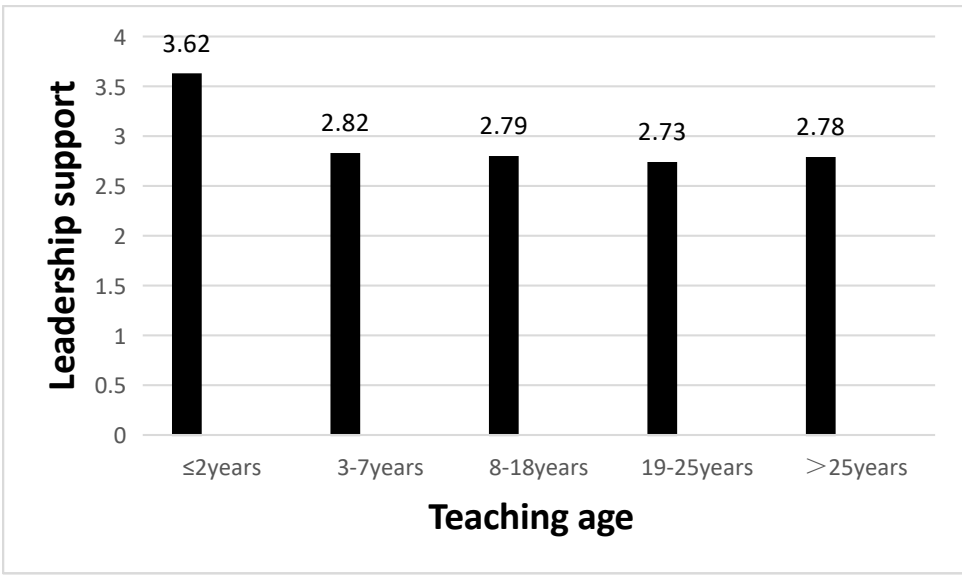

Figure 2 Comparison of differences in coaching age for PE teachers

\subsection{Analysis of Job Satisfaction of PE Teachers with Different Professional Titles}

The median test method was used to conduct comparative analysis of different titles of primary and secondary school PE teachers. The results are shown in Table 8.

Table 8 Examination of Job Satisfaction of PE Teachers with Different Academic Degrees

\begin{tabular}{cccc}
\hline Variable name & Chi-square test & DF & P \\
\hline School system & 4.793 & 2 & 0.001 \\
Remuneration and benefits & 6.889 & 2 & 0.001 \\
Work itself & 3.569 & 2 & 0.192 \\
Leadership support & 5.239 & 2 & 0.223 \\
working environment & 7.610 & 2 & 0.199 \\
Human relations & 1.609 & 2 & 0.211 \\
Total satisfaction & 4.175 & 2 & 0.642 \\
\hline
\end{tabular}

In terms of professional titles, it can be seen from Table 8 that there is a significant difference between the two factors(the school system and salary \& welfare).As can be seen from Figure 3, in the dimension of the school system, the degree of satisfaction of senior titles teachers is significantly higher than the primary and intermediate levels. The level of professional titles is usually proportional to the age and age of the teachers. The teachers with higher professional titles will have correspondingly higher ages as well as the teaching ages. They will have higher status in units and greater influence. They will be involved in school management and democratic decision-making. The right to speak is even heavier. Therefore, teachers with senior professional titles are more satisfied with the school's management system than the primary and intermediate levels. It can be seen from Figure 4 that in the pay and benefits dimension, the satisfaction score of senior teachers is 3.37, which is much higher than that of teachers with other titles. With the increase of professional titles, the higher the pay and benefits. There is not much difference in satisfaction between the teachers of primary and intermediate titles on the pay and benefits scale, and the total is low, only about 2.8 points, which is a level below the middle level. In most scholars' research on teacher satisfaction, the satisfaction level of salary and welfare is generally low.In recent years, the education industry in China has developed rapidly. Not only does the state pay more and more attention to the education industry, but also the quality of education for schools in the society is getting higher and higher. As a result, the intensity of teachers' work in China has also increased. However, teachers' wage income There has been no corresponding increase in the level, 
resulting in teachers' lower satisfaction with pay and benefits.

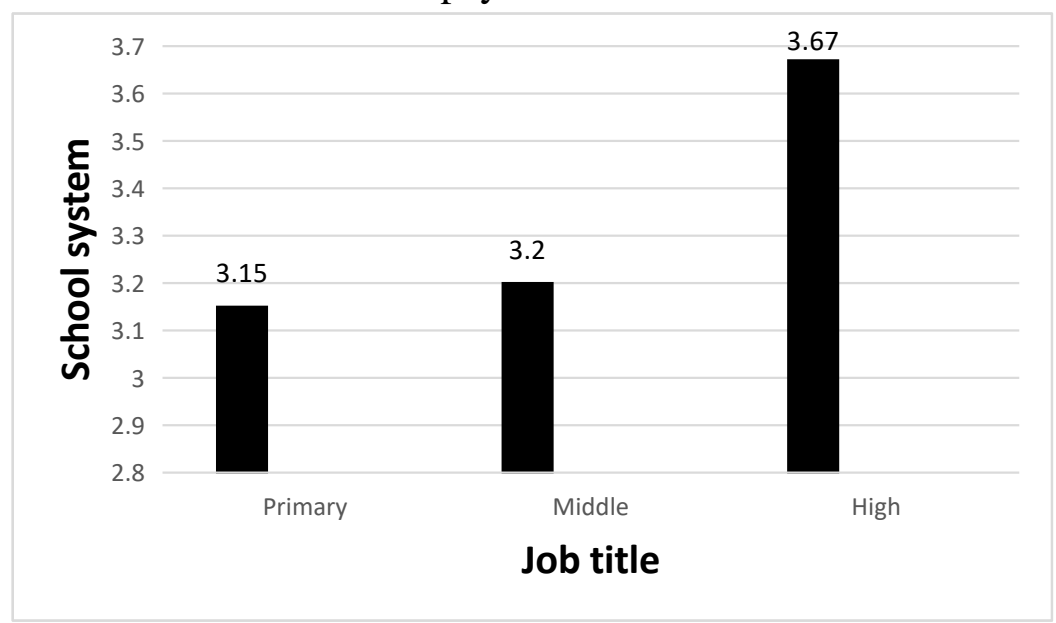

Figure 3 Comparison of PE teachers with different titles

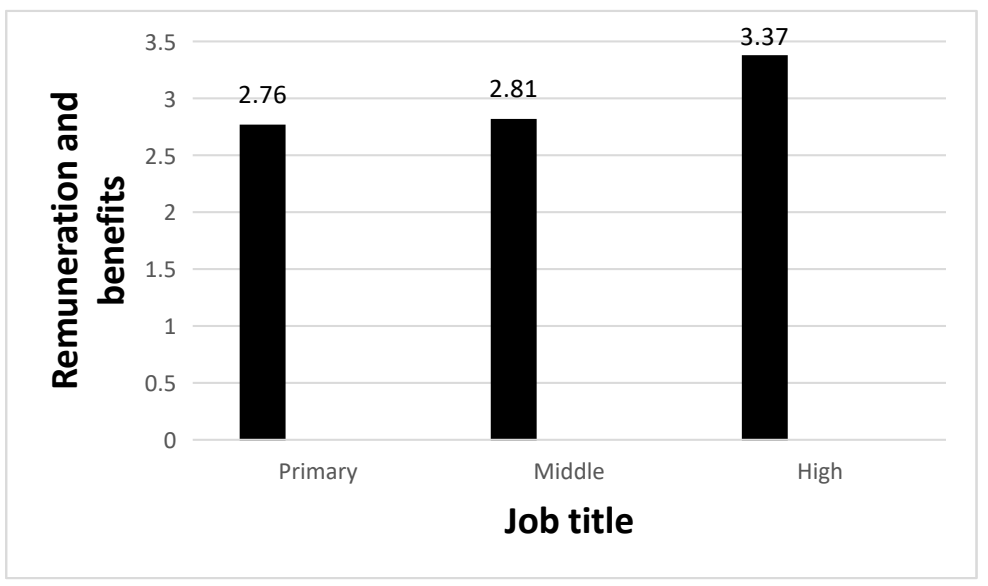

Figure 4 Comparison of PE teachers with different titles

\section{Conclusion and recommendations}

The survey results show that the overall job satisfaction of primary and secondary school PE teachers is of medium level, with the highest degree of satisfaction in both the work itself and the interpersonal relationships, and the school system is in medium level. However, the pay packages, are also belonging to the lower middle level of the degree. And the satisfaction of male PE teachers in work is far greater than female ones., and there is no significant difference in other dimensions. The young sports teacher's satisfaction with the age of 0-2 years is supported by leadership support. In terms of salary and welfare, the degree of satisfaction of senior teachers is significantly higher than that of junior and intermediate titles. In the two dimensions of school system, salary and welfare, the satisfaction of senior teachers is significantly higher than intermediate teachers and junior teachers.

Here are some suggestions:(1) Supporting the awareness and implementation of the PE teachers' working supports;(2) Improving the physical education environment;(3) Building the harmonious classroom atmosphere;(4) Establishing the available compensation system according to the current situation. 


\section{Acknowledgements}

I extend my deep gratitude to all those who have offered cordial and selfless support in writing this thesis. Supported by leisure sports industry development research center of Sichuan province(XXTYCY2017C04); Chengdu university youth fund project of 2018(2018XSB02).

\section{References}

[1] Liu Rongmin, Sun Xiaoyan, Investigation and Countermeasures on Job Satisfaction of Rural Primary School Teachers_-Taking Rural Teachers in a County as an Example, J. Researches in Education and Teaching, 2014, 28(7):35-38.

[2] Zhou Yanli,Zhou Yi.Study on the Job Satisfaction of Senior High School PE teachers in Henan Province,J. Journal of Guangzhou Physical Education Institute,2003,23(4):93-94.

[3] Landy FJ. Psychology of work behavior (4th. Edt.), M. New York: Wadsworth Inc.1989:85.

[4] Zhu Geweimin. Investigation and Analysis on the Status Quo of Job Satisfaction of University PE Teachers in Zhejiang, Shanghai and Jiangsu Provinces J. Journal of Beijing Sport University, 2001, 24(1): 81-82.

[5] Wu Minglong. Questionnaire statistics practice - SPSS operation and application M. Chongqing: Chongqing University Press, 2015: 217.

[6] LIU Qingliang, ZHANG Chaohui. The relationship between college students' sports leisure satisfaction and motivation based on SEM analysis J. Sport Science,2009,29(4):80-83.

[7] Shao Xishan, Liu Yao. Occupational burnout in the career cycle of college PE teachers J. Journal of Physical Education, 2008, 15(8):57-60. 